\title{
Migrating from traditional grid to smart grid in smart cities promoted in developing country
}

\author{
Omnia Saidani Neffati ${ }^{\text {a }}$, Sudhakar Sengan ${ }^{\text {b,*, Kalavathi Devi Thangavelu }}{ }^{\text {c, }}$ \\ Sharma Dilip Kumar ${ }^{\mathrm{d}}$, Roy Setiawan ${ }^{\mathrm{e}}$, Mohanraj Elangovan ${ }^{\mathrm{f}}$, Devi Mani ${ }^{\mathrm{a}}$, Priya Velayutham ${ }^{\mathrm{g}}$

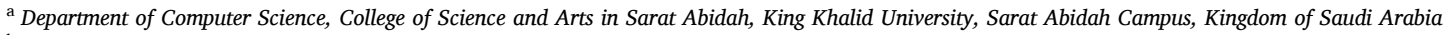 \\ ${ }^{\mathrm{b}}$ Department of Computer Science and Engineering, PSN College of Engineering and Technology, Tirunelveli-627152, Tamil Nadu, India \\ ${ }^{\mathrm{c}}$ Department of Electronics and Instrumentation Engineering, Kongu Engineering College, Perundurai-638060, Tamil Nadu, India \\ d Department of Mathematics, Jaypee University of Engineering and Technology, Guna-473226, Madhya Pradesh, India \\ e Department of Management, Universitas Kristen Petra, Indonesia \\ ${ }^{\mathrm{f}}$ Department of Computer Science and Engineering, K.S.Rangasamy College of Technology, Tiruchengode-637215, Tamil Nadu, India \\ ${ }^{g}$ Department of Computer Science and Engineering, Paavai Engineering College, Namakkal-637018, Tamil Nadu, India
}

\section{A R T I C L E I N F O}

\section{Keywords:}

Smart grid

Sustainable energy

Smart city

Solar

Wind

Energy storage

\begin{abstract}
A B S T R A C T
Smart Grid is a term that encompasses the economic benefits of an intelligent and advanced power grid to reach changing responsibilities related directly to sustainability and energy efficiency. Considering the shortfall of alternative fuels in developed regions, the new smart grids, in order to have access to their environmental hazard, show that the average non-renewable and renewable energy sources can be integrated to reduce environmental disasters to improve production costs significantly. In order to provide reliable, secured, and cost-effective power grid functions, infrastructures can quickly and effectively co-ordinate power-sharing between several renewable energy sources freely accessible and economically demand costs. This article reviews the conceptual model, goals, architecture, potential benefits, and power grid issues with a complete and accurate understanding of the different defenders and people involved in the worldwide region scenario. The article examined energy and transmission issues, including smart grids and grid barriers, comprehensively.
\end{abstract}

\section{Introduction}

A Smart City is a city atmosphere that uses many IoT sensors to collect data and then utilizes insights gained to manage the assets, services, and resources effectively. It includes information about people, equipment, buildings, and assets that are processed and examined for monitoring and management of transportation systems, Electric power stations, utilities, water distribution networks, waste management, criminal activity detection [6], information systems, school education, library system, healthcare, and other community-based services.

The smart city plan combines Information and Communication Technology (ICT) and different real objects connected to the IoT network to attach the city and service with citizens [32]. The smart city's technological features help the city officials touch with the city's infrastructure and the municipality and watch its daily activities. ICT is used to improve the feature, performance, and urban service interactivity, reduce cost and resource use, and enhance public-government contact [20]. Smart city applications for urban flows are created and enable real-time response. Therefore, a smart city is better prepared to face the challenges than a simple "transactional" interaction with citizens [3]. However, the term itself remains ambiguous and open to numerous interpretations [15-17].

In many countries, society is migrating towards modern technology, resulting in electricity generation's need to avoid environmental risks like security, health care, business, marketing, etc. [21,25]. This makes researchers to move towards advanced technologies for developing countries to avoid risk assessments while increasing power consumption in day-to-day activities

Through the advancement and the use of emerging technologies in the nearby area, especially innovations which create smart performance,

\footnotetext{
* Corresponding author.

E-mail addresses: oneffati@kku.edu.sa (O. Saidani Neffati), sudhasengan@gmail.com (S. Sengan), kalavathidevi@gmail.com (K.D. Thangavelu), dilipsharmajiet@

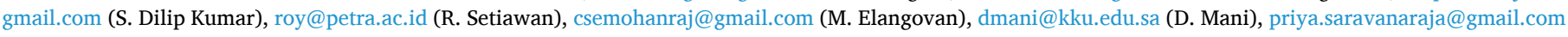
(P. Velayutham).
} 
the Smart Cities Mission works to encourage financial development and increases human living quality. The area-specific development (renewal and redevelopment), including slums, will turn existing slums into more planned areas, thus improving the entire city's life span. In order to accommodate the growing population within urban areas, new areas (Greenfield) will be established around cities. Applying Smart Solutions will allow cities to improve infrastructural development and services using technology, data, and information. Comprehensive development will enhance the quality of life, generate jobs, and improve everyone's income, particularly for the needy and underprivileged, leading to inclusive cities.

In the smart city, internet services' energy consumption requires more knowledge towards traffic and network data transfer. For this reason, the energy is transferred in the form of a network segment [44] based upon the services through virtual and augmented reality applications. The root cause of energy consumption is smartphone applications like video chat, video play, etc.; the smart grid's essential advantage in power energy systems is generating more electric grids for computerized devices and technology. It will be more efficient for power transmission at the time of disturbances in transmitting electricity, and also it highly supports integrating large-scale renewable energy systems.

The '100 Smart Cities Mission' was started by the government of India in June 2015. These cities should have improved infrastructure, expand housing for everyone, and develop open spaces. In 2020, the Union government had progressively expanded the Smart Cities Mission to include all 4000 cities following a phase-out in 100 cities.

The availability of smart technological innovations and IT remedies increases only with a straightforward structure in advancing these virtual reality cities. While this number of Smart City innovative technology developers and investors grows, all developers still find it very difficult to find several other significant issues elsewhere.

Here are a few common issues of Smart City solutions currently facing and how the development team can start tackling these obstacles to success.

\section{a) Challenge \#1: Infrastructure}

The replacement of decades-old infrastructures such as subsurface wiring, steam supply pipes, tunnels for transport, and high-speed Internet installation already pose challenges for major metropolitan areas. Wireless broadband is on the rapid increase, but in major cities, the access is limited. There is limited funding, and approvals may require years for new infrastructure projects. Installing new sensors and other enhancements cause problems for cities' citizens temporarily though still frustratingly.

Developers can install and use smart technology easier in the earliest stages of development by addressing these challenges. In the meantime, developers and technology companies can quickly make our cities smarter by implementing readily available easy-to-install hardware by considering the solution, which means the complete solution implementation.

\section{b) Challenge \#2: Security and Hackers}

Everybody is a little more concerned and skeptical about technology and safety in the recent discussion about cyber terror threats to the vulnerable and obsolete power system.

Smart Cities are spending a lot of money and resources on safety measures, while technology companies are developing solutions to protect them against hacking and cybercrime with new mechanisms. Since blockchain is the topic $d u$ jour of the day for the technological industry, numerous developers are searching for ways to integrate these encoding technologies safer for newer technologies

c) Challenge \#3: Concerns about privacy
There is a balance between living standards and privacy violations in significant cities. And while everyone wants a satisfied, quiet, and renowned high, none of them wishes to feel that the government monitors them all the time. Cameras on all edges of the highway can help avoid crime and make law-abiding citizens nervous and fearful. Another significant issue is the volume of evidence collected from all people who live in sensing devices.

Developers could further reduce the anxieties of intelligent city residents by increasing their solutions with transparency and education. By taking into account the community and considering how new technologies can react, the enterprise can benefit from people to whom their solutions aim. Local officials and local authorities must, of course, participate in the development and training aspects.

\section{d) Challenge \#4: Community Education and Engagement}

For a smart city to emerge and succeed, there is a need for "Smart" citizens who work with new technologies and actively benefit from them. With every new city-wide technology project, the community needs to be educated about the benefits of the implementation phase. It can be carried out by utilizing many individual town-hall meetings, email campaigns, and an educational web portal that keeps citizens active and up-to-date [8].

If social experience plays a role in the overall decisions affecting daily life and is clearly and thoughtfully transmitted, it is better suited by using the technical methodology and motivating other people to use the technology. This is vital for the success of a Smart City.

\section{e) Challenge \#5: Being socially inclusive}

It is essential for Smart City's planning to consider the affluent and technologically advanced groups of people. Instead of dividing more people following income or education, technologies should always bring people closer together. In conjunction with the other issues raised in this article, thinking of these communities will encourage a solution beyond technology-oriented users.

Urban development is challenged by its problems and lack of resources like energy, water, waste management, aging of existing buildings, health-related issues, etc., as demonstrated in Fig. 1 [10,38]. In the last ten years, the smart city idea was highlighted and proposed by researchers as an optimal solution to urbanization problems. In this context, smartness is defined by using information and communication (ICT) technologies to improve the standard of living in metropolitan areas and urban residents there from various perspectives.

However, the use of ICT in city settings does not constitute a smart city [16]. For a smart-city method, there is an extensive definition of the smart city as a connecting infrastructure to improve city intelligence [14], balancing demand, and providing different features [41]. Cities constitute $75-80 \%$ of world energy consumption [7,27], leading to a production of $80 \%$ of gaseous greenhouse emissions [28] and keeping that in mind, the renewable essence of renewable energy sources is best suited to recent global energy requirements in sustainable cities besides the lack of fossil energy and the cities' growing population. The key and vital elements that support the idea of a sustainable future city are smart grids (SG's) or the new version of conventional 'dumb' energy infrastructures [7]. It blends non-renewable and renewable sources of energy, thereby minimizing environmental issues. In the meantime, they benefit from lower electrical power prices and stable energy supply [24,33,34,39].

In the traditional non-smart system, there is insufficient monitoring/ real-time control, which provides SGs with a demanding opportunity to operate as real-time solutions. For a smart city, a new generation of smart grids and power systems can manage the energy of buildings undergoing modernization by combining smart grids and buildings to produce energy performance/generation [31]. Indeed, by using the available resources [13], the smart grid introduces additional facilities 


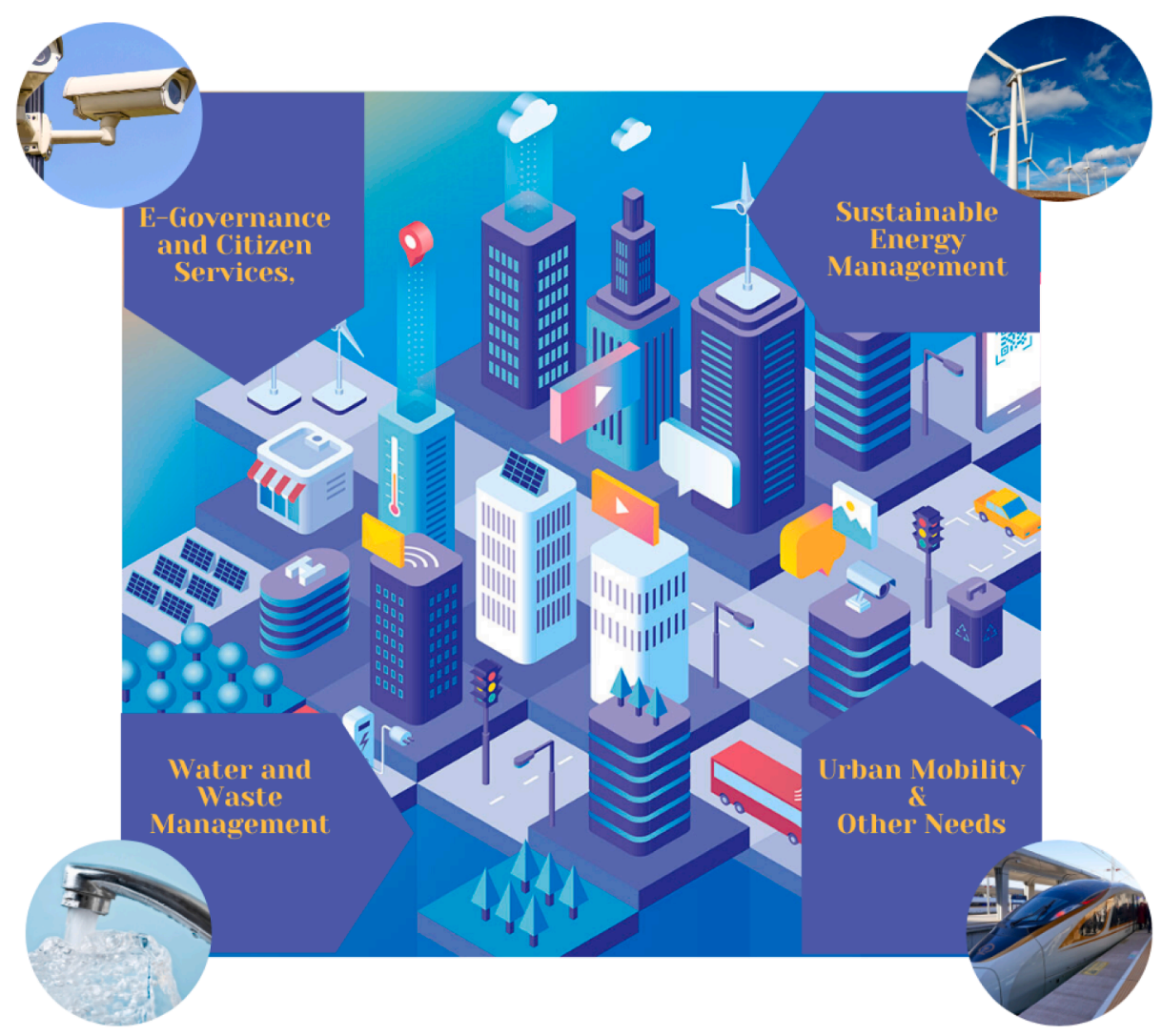

Fig. 1. Core Smart City Infrastructure Challenges.

to smart homes $(\mathrm{SH})$ residents and shows excellent potential for their business and economic value [23]. Allowing smart grids to be supported and taking their essential services into account for other infrastructures make them an example of how smart cities can be implemented.

In brief, the smart perception of the city addresses the emerging challenges of urbanization in the future. A comprehensive review of smart plug technology, which could contribute to green energy, smart grids, and smart cities, was released [36]. Researchers examined four main features of intelligent grids by examining 317 smart grid applications. A detailed review [37] is provided for state-of-the-art technologies and associated works on smart grid models, theory, distribution, and use. Simultaneously, some 2009-2018 research articles were reread [11] and combined according to their research work regarding smart grid consumer categories' classification. The current state-of-the-art [12] Computational Intelligence (CI) system was concentrated in smart power grids and classified different CI techniques for intelligent load forecasting.

However, because of technological, economic, and governmental obstacles, much work has to be done. This paper is designed to understand the smart grid's responsibilities as they play an important role in smart city development. Initially, we will describe SGs in greater detail and illustrate their significance in smart cities, following the role of micro-nano, solar, wind, energy sources, and smart water grids by smart city areas. Finally, the leading research in the smart city in Europe will be reviewed. For the optimum result, although several articles on the issue were published and covered different aspects of smart grids, a detailed analysis was not done simultaneously to identify all the above significant problems.

In 2015, the prime minister of India allocated 98,000 crores (US\$ 14 billion) to 100 smart grid projects based on the roadmap of the Ministry of Urban Development. The energy distribution system is currently mono-directional, fixed consumer charges, and generally uses simple meters that can't exchange bidirectional data. In some instances, they are built for remote reading but mostly lacking in the bi-directional digital communication network.

Advanced Metering Infrastructure (AMI) addresses these challenges by bidirectional exchanging information between the power generating grid and the consumer. The use of smart meters helps track the actual and real-time electricity consumption by giving dynamic price data and their carbon emissions contributions and helping users make smarter decisions [4,31].

Alternatively, it will be easier for energy suppliers to manage production and consumption. The consumer has the freedom to use peak demand management to control their high-wattage machines, such as the air-conditioning system, water heater, pool pump, and dry garments. Electric Vehicles (EV) are increasingly popular, making it possible for smart grids, for example, for the "spinning reserve" of wind turbines, to identify and consider the produced energy/stored from the consumer's area. By adaptive feedback loops resulting from smart grid digital communication, the 'foolish' technology is changed into an intelligence system [4] (Fig. 2).

The main features of SGs begin with the modernization of the power system through live tracking, automation, and auto controlling problems. The second-class target is to update consumers from the energy consumption point of view, the real-time costs, and smart decisions. Eventually, we need a combination of renewable and non-renewable to supply reliable and sustainable energy resources [7]. Some significant problems, such as long-haul transportation, energy loss [9], and related costs are minimized by generating and distributing energy via intelligent energy systems. It is accomplished with smart loading and automation, including home, leading both at home and industrial applications for improving energy efficiency, comfort, and security [22,29,40]. This model's primary motivation is to avoid environmental hazards, save energy, and provide reliable energy access. This motivates us to move towards deep learning models for power consumption in the smart city to enhance and reduce energy utilization over the mobile network. 

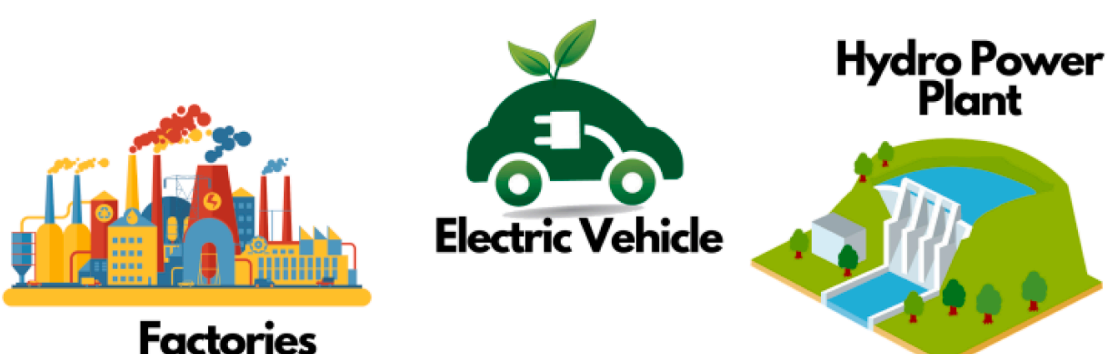
Plant
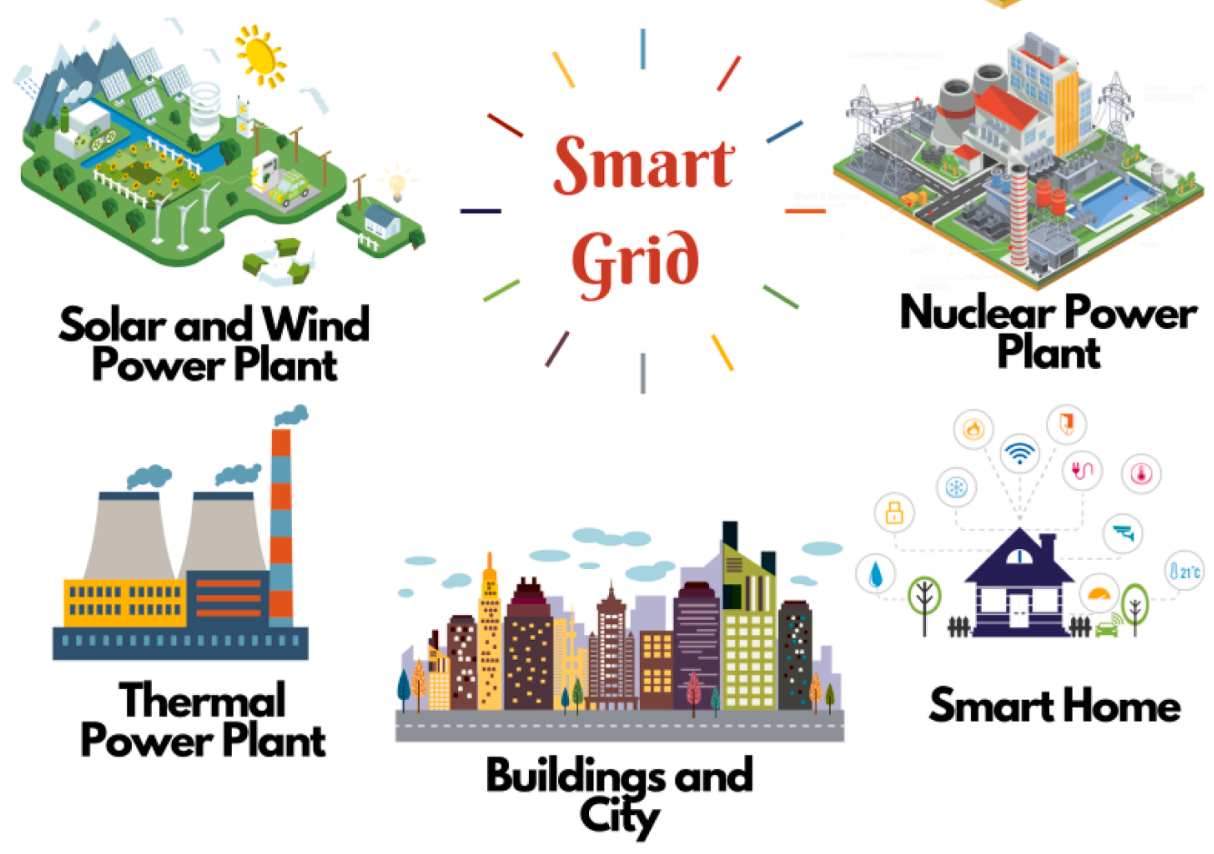

Fig. 2. Features of Smart Grid.

Despite SG's technical problems, predictable technologies can find an appropriate solution. The other challenges are primarily institutional, market, and social engagements, accompanied by increasingly smart grids. A comprehensive analysis is [23] investigated and decided to take a wide range of factors and discovered that all key elements are integrated into a widely accepted outline by the severe challenges. The most crucial factors [2] in the energy transition are geography and infrastructure.

Various methods are available to reduce communication networks' energy consumption through internet services that process systems with different delivery modes in BS [44]. This controls and reduces total network energy consumption while assessing data and signaling components. The smart city consumes much more energy for data transfer in mobile networks by end-to-end energy consumption.

The smart grid's key advantage in power energy systems is to generate more electric grid for computerized devices and technology. It will be more efficient for power transmission at the time of disturbances in transmitting electricity, and also it highly supports integrating largescale renewable energy systems.

The article is organized as follows: Session 1 comprises introducing the smart city with a smart grid system and the challenges. Session 2 consists of various smart grid technologies available in the smart city and how it demands the responses towards emerging technologies, and session 3 shows India's sustainable energy integration in smart cities. Session 4 comprises sustainable energy production challenges, with session 5 of smart energy systems' energy transmission and distribution challenges. In session 6 , the conclusion of sustainable energy implementation over the mobile network is shown.

\section{Smart grid technologies}

The term "Smart Grid" implies implementing digital innovations, sensor systems, and ICTs, which is good enough to make energy consumption accurate and useful. The smart grid includes consumer (interacting consumers) and the grid technology, which is less visible to consumers (transmission and distribution). Hardware and software $[19,35]$ are also featured in Smart Grid technology.

A design of multiphase interleaved pulse power supply and energy recovery and inductive storage (MIEF-PPS) [42] was proposed for transforming multiphase via circuits. The induction energy is getting back to the input source, and it doesn't discharge the load to save power consumption. A power-saving problem for mobile networks are modeled through in-house equipment for various base station load, and network traffic volume is built to manage traffic over mobile networks. This positively supports for BS power control is made by using Q-learning. Here, a deep convolutional neural network- Q agent [43] was designed to control BS loads.

One of the definitions of smart grids is the combined use of advanced communication and control technologies to integrate various technologies, products, and services from smart grid generation, transmission, and distribution. This concept is shown in Fig. 3.

A wide range of innovations must be created and tested to accomplish a developed and modern smart grid. As mentioned in the following, these systems were commonly categorized into key related technologies.

- Smart Utilizations: Smart sensors can choose whether to include energy based on user preferences. This can lead to a reduction in relatively low power generation costs. For example, smart sensors, 


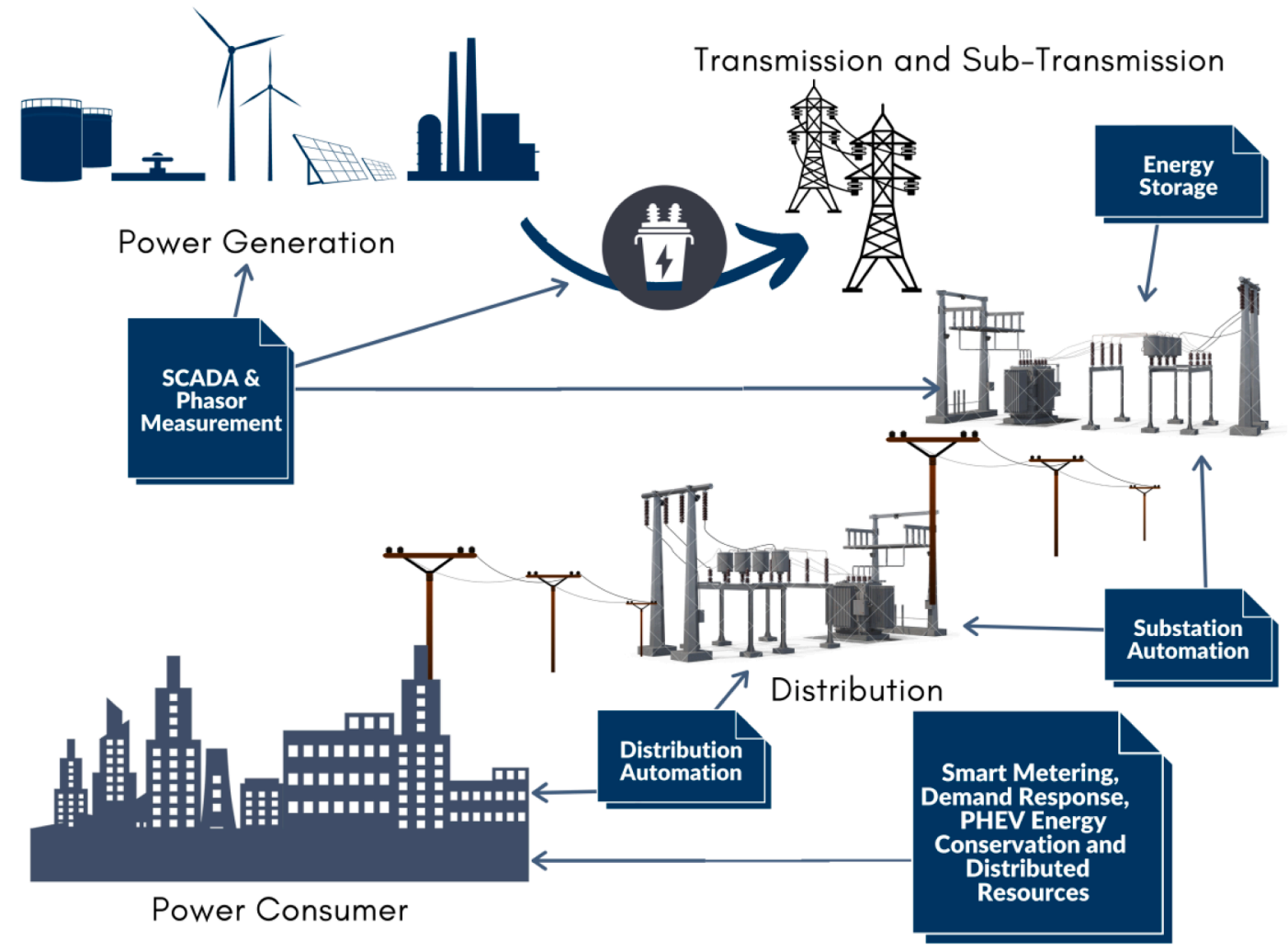

Fig. 3. Concept for smart grid systems for control and communication [5].

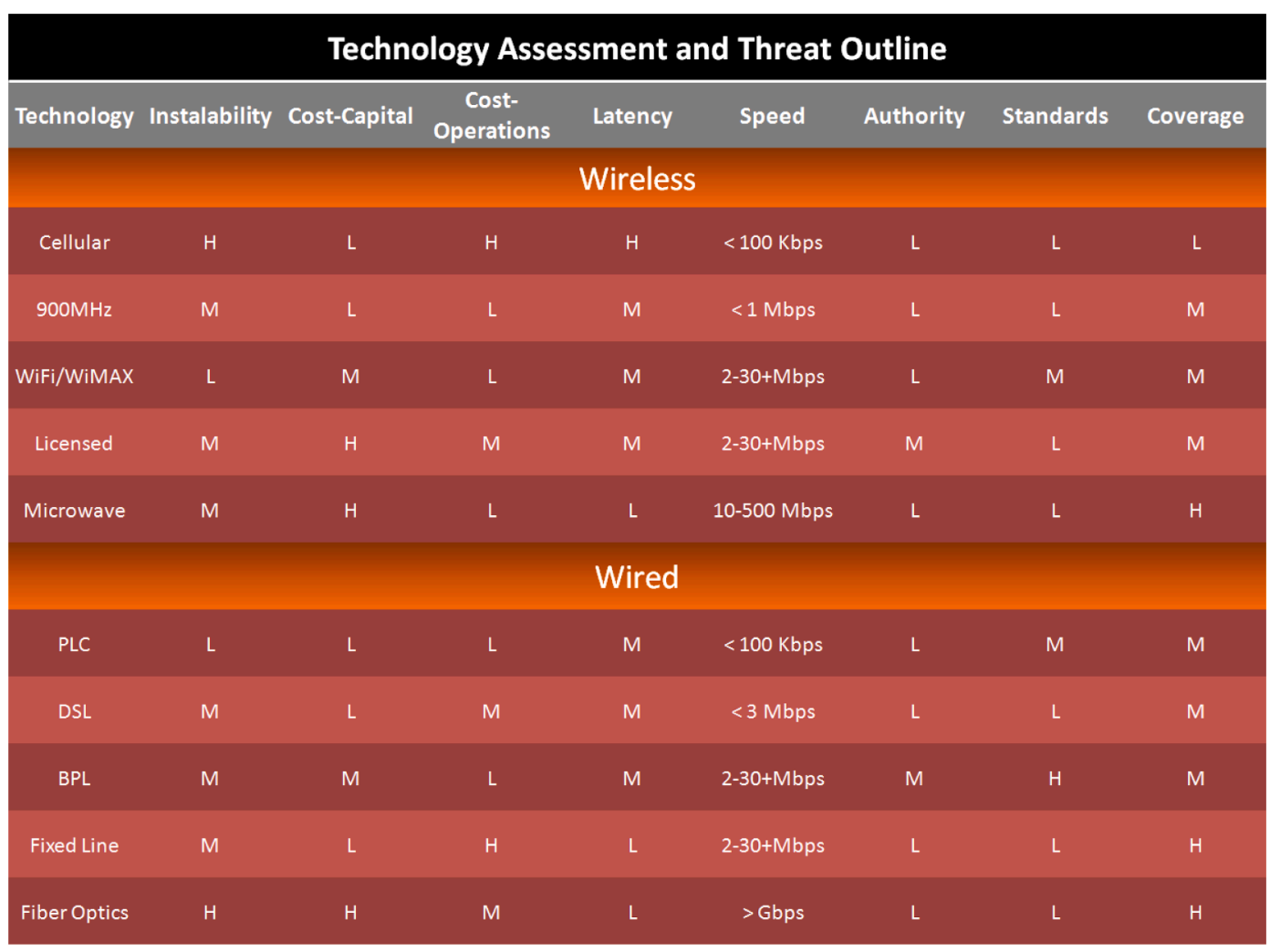

Fig. 4. Key considerations of a communication technology. 
like a heat detector, control boiler heat clearly - the programmed average temperature in thermal power stations.

- Smart Power Meters: The smart grids provide power distributors and device manufacturers with 2 factors to automatically collect the billing sensor data defaults and send repair crews to the specific time much faster and more efficiently.

- Smart Grid-Substations: Sub-stations are often used for directing and maintaining time-sensitive and sensitive operational data such as energy into rotational, boost converter productivity, safe operating system, and status of the transformer. Smart substations are also allowed to partition the flow pattern in several particular directions. Substations need complete and accurate, sophisticated tools, including transformers, switches, condenser banks, circuit breakers, network relays, and many other system networks.

- Ultra-behavior Cables: These components are used to provide the long-range transmission of power, automated control, and advanced analytics that can detect errors or even predict the weather and weather-based cables or failures.

- Integrated Communication: The key to the smart grid system is an embedded exchange of information. It must fulfill the system's realtime demands as rapidly as thinkable. It probably depends on the need for smart grid connectivity, and many innovations such as Programmable Logic Controller (PLC), Wireless, Mobile, SCADA, and BPL, have been used.

Integrated Communications Key Considers (Fig. 4):

- Facility to deploy

- Response time

- Standards

- Capacity data transmission

- Safe.

- Capacity for network coverage

- Phasor Measurement Units (PMU): For synchronization, use a sensible place component to measure the electrical waves on an electrical grid. The time-synchronizer allows multiple remote measuring points on the grid to be synchronized in real-time measurements.

\section{Condition of demand response analysis}

High-cost power plants are needed to meet the highest demand. In the past, the strategy used to meet electricity demand was to add more generation. Currently, demand management is more focused on energy distribution to decrease demand points. The smart grid approach implies something more than one emerging technology or a consistent range of energy sources [18]. A core principle in the performance in terms of energy availability was demand response (DR), which mostly reduces limited supply in crucial circumstances. Changes in power generation accompany DR, regular electricity consumption patterns by end-users, or benefits to improve renewable energy use at peak hours [1]. Load management is characterized as a sequence of objectives to regulate, directly or indirectly, the patterns of power consumption by targeted customers in order to minimize high demand. This control and alteration enable the delivery mechanism to increase supply more successfully using the accessible production and transmission capacity [30]. In this procedure, when the situation is critical, energy utilities can deactivate the consumer. The direct monitoring of fossil-fuel production can also be used to minimize requirements for capacity, operating cost, and reliance.

"Valley Filling" is a load creation in the peak period. The average electricity price is thus reduced. "Load Shifting" moves maximum loads for other time intervals without inherently changing social consumption. The advantage of "Peak Clipping" and "Valley Filling," combined with moving existing loads during off-peak hours, is combined with this method [30].
DR programs have an essential responsibility to reduce maximum consumption for grid power during peak times. Consumers can move loads, as well as improve the situation. The supply voltage ignores errors and power outages of the electrical grid, which reduces the chances of environmental stresses. Designed to enhance DR energy protection boosts the quality of working life. The DR also eliminates the need for financial generators and helps to reduce energy bills [18]. There must have been direct communication among both energy users and service providers in good enough conditions that provide potential customers with real-time information. To respond to demand events, consumers should be able to examine their demand for electricity in real-time. Advanced metering infrastructure (AMI) and other technology allow users to measure the energy demand in real-time and further enhance DR resources' daily use [26]. Using deep learning methods for smart grid is to make the communication and network systems into the automated system and power-saving while transmitting through mobile networks. Recently, IoT plays a significant role in communicating network devices in a smart city with high-performance speed.

Therefore, it is clear that an automatic energy management system is necessary for DR programs so that consumers can have more flexibility.

\section{India's sustainable energy integration in smart cities}

It is taken into consideration India's tokens concerning energy resources. India has the 5 th most significant coal reserves in the country, attempting to hold 267 thousand pounds. But only 20 billion tons (Source: TERI) is extractable. India's oil and natural gas reserves (894 K barrels/day production compared to $3727 \mathrm{~K}$ Barrels/day consumption 2013 ) is less than $1 \%$ of the world's proven reserves (All data sources: BP World Energy Report 2014 Statistical Review). This advertisement to convert energy is certainly not very good. It is a fundamental economic measure that probably needs a critical response. Hence, more funds must be diverted to renewable energy, power efficiency, power storage methods for erection, research, development, and building competency. But fossil fuel will stay here, if not longer, for several decades. For this reason, several research, development, and deployment (RD\&D) technologies must be considered during the phase of transition from fossil to renewable energy sources (Fig. 5 and Fig. 6).

\section{Sustainable energy production challenges}

\section{Combination of fossil energy with CO2 Capture and Storage (CCS)}

By capturing the emission of point-of-source spreading into the environment, CCS prevents CO2 emissions and fills them in storage space like atmospheric creation of mineral carbonates. But, capturing, compressing, and transferring to the storage space requires $10-40 \%$ more fuel, sinking in efficiency due to additional fuel requirements. This

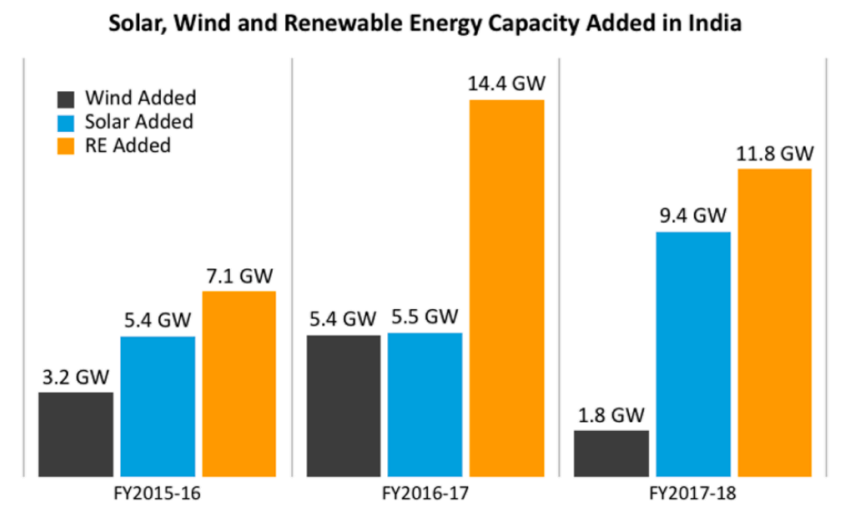

Fig. 5. Energy capacity in the form of solar, wind, and renewable energy added in India. 


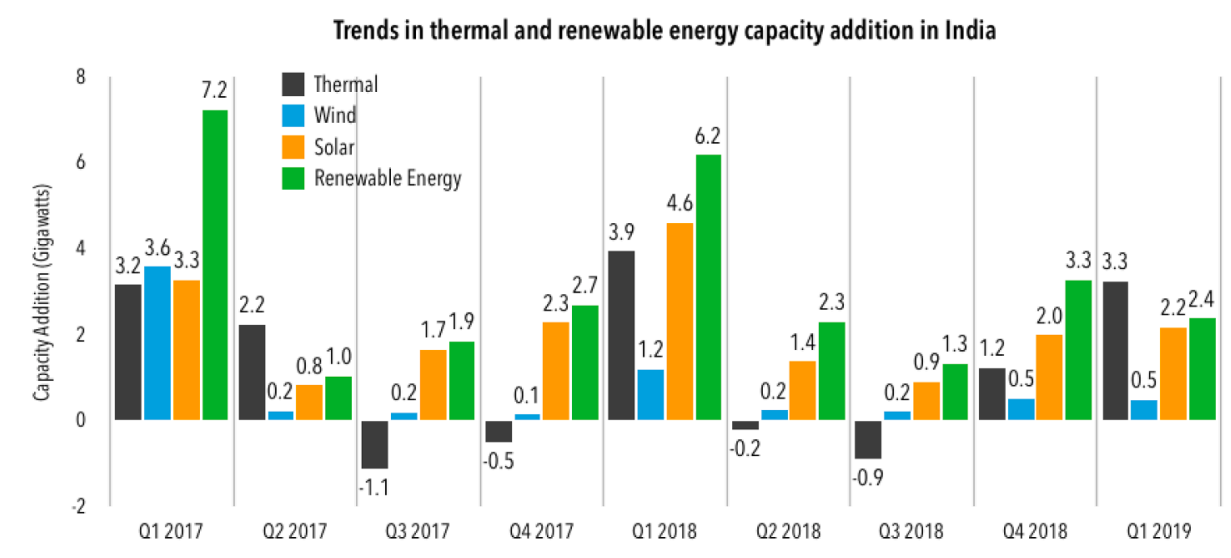

Fig. 6. Energy addition in Indian grid for the year 2017 to 2019.

aspect reduces the significance of this method in terms of cost-efficiency.

\section{Shale (Natural) gas: A transition fuel}

Natural gas generates at least half of the $\mathrm{CO} 2$ emissions for the same amount of energy produced. Fortunately, recent research suggests that natural gas is just as bad as coal if gas leakage is $3.12 \%$. Leakage of over $3.12 \%$ from decomposition to energy utilization has indeed been claimed (Source: University of Cornell). However, Lawrence Cathles disputed this claim, stating that further studies conducted by the Agency for Eco-Protection put the leakage at less than 1.5\%. Additionally, IPCC's 5th AR, supported by ample proof, advocates an alternative for "a worldwide and moderate thermal power stations that are packed with recent and efficiency combined natural gas or thermal power combined power stations provided that the accessibility of natural gas mitigate the brief emission while extracting and delivering."

\section{Underground coal gasification (UCG)}

UCG is supposed to viable in India. It is used when the replenishing of coal is not possible either for practical or commercial purposes. According to the 2007 World Energy Council Survey by the National Resources, UCG can exploit a possible coal reservation of 600 billion tons. The UCG's easy to exploit U.S. mineral reserves can be nearly doubled by $300 \%$, as per the Lawrence Levermore National Lab. Given that most coal reserves in India are uncomplicated and UCG could only be the currently required technology. The social and environmental effects of UCG are positive. This process does not require mining, and also, a threat to life, flora, and fauna has been considerably minimized. No surface damage is caused due to the absence of an extraction process. Noxious gases like SO2 and NO2 are not released into the atmosphere due to minimal surface damage. The use of UCG with CO2 Capture and Storage (CCS) is possible. There are several operational concerns regarding technology on the flip side. Therefore, judgment needs to be tempered because of recent events in Australia, where the government charged Linc Energy UCG with environmental damages in 2014. Furthermore, in 2010, the Atomic Sciences Bulletin stated that if used without CCS, UCG would result in a quadrupling of $\mathrm{CO} 2$ emissions.

\section{Renewable energy generation}

Compared to the relatively emerging situation with different fossil fuel energy reduction options, we can see that there is still a limited scope for locating these technologies. Therefore, it is highly desirable to switch to renewable sources with increased $R \& D$ investment for renewable energy sources.
Wind

As of December 2018, India has a $22.5 \mathrm{GW}$ installed capacity. The Center for Wind Energy Technology and MNRE has measured wind power potential in India at 100GW. India's other offshore wind energy industry is said to have between $350 \mathrm{GW}$ and $500 \mathrm{GW}$ of potential. Although the best wind farms in India are being utilized to strengthen incremental micro-sites' capital, offshore wind energy's undiscovered potential has been given an opportunity. More wind turbines can also replace smaller obsolete lower-capacity wind turbines at old locations. The Indigenizing technology and the linkage between renewable energy development and "Make in India" would support to decrease in the country's capital costs and net costs for the operation.

Solar

As of December 2018, India has a $3.06 \mathrm{GW}$ installed capacity. The National Institute of Solar Energy reports that India has probably 750 $\mathrm{GW}$ of solar power. It would have become ubiquitous to use solar rooftop modern technologies; solar and wind power usage would be enhanced with factor changed. More systematically institutionalized and targeted financing incentives for the adoption of this green power should be provided.

\section{Waste to energy}

In India, 62 million tons of waste is generated. It is expected that by 2050 , this number would reach 436 million tons. India's municipalities are currently lacking a properly institutionalized functional waste disposal mechanism. These outcomes in hazardous waste are $81.23 \%$ of the generated waste. The approximate request for such waste accommodation would include an 11-meter-high dumping yard in London if dealing with this garbage is not evolved by 2050. India has only 8 Waste to Energy (WTE), 29 Refuse-Derived Fuel (RDF), 172 bio-methanation, and 279 compost plant factories. Many WTE plants have died because of a wide range of reasons such as lack of thorough research, disaster and quality and availability waste, lack of awareness, economic environment, and Non-My Back Yard problems. As per a public sector taskforce, India's resource consumption possibility is expected to increase to be around $556 \mathrm{MW}$ by 2050. It might be moderate, and that shouldn't lead to significant possibilities getting ignored. The WTE is not just an energy industry and thus should be shown as complementary to industries such as waste disposal, healthcare, cleanliness, and water. The high efficacy and cost benefits of waste energy are exceeding attempts are considerably higher than the small percentage of $556 \mathrm{MW}$.

\section{Energy transmission and distribution challenges}

Smart grids and meters

India's confrontation with sustainable energy has not confined itself 
with generation; however, it expanded to the T\&D segment. A report from the Central Electricity Authority (CEA) reveals that in 2013 there was a loss of $23.14 \%$ of electricity. This is a contrast to the 2011 report that showed an average of $9.18 \%$ globally. A-Line of $765 \mathrm{KV}$ between Raichur - Sholapur was synchronized in December 2014 by India's Southern Grid. Recently, India started to pay serious attention to smart power grids and hence invested in the erection of the same. We had 14 approved smart grid pilots. The concepts of techno-commercial feasibility will be evaluated as evidence and then extended. The smart grids would primarily be responsible for combining technical and business losses, integrating renewable energy, managing high loads, improving power quality, creating microgrids, and distributing power. Although Smart meters are vitally important to the smart grid infrastructure, they can be viewed as parallel with reducing losses as an independent intervention area. The smart meters can enable energy to be returned to the grid from surplus households (say solar rooftops). They can also help households monitor their costs and reduce electricity bills.

\section{Indian context demand response}

The immediate reaction to supply is in India in its evolving stages. The advantages in western European countries usually involve reducing energy blackouts and reduced electricity cost, which is a need to develop raw materials' supply and integrate hybrid cars and renewables. In order to implement the Demand Response strategies, a regulatory framework must also be in place. However, despite the enormous variability of potential customers to be represented in India, the acceptable consumers to be obtained must be determined to give a response to guarantee that the scheme succeeds. Level of awareness and freedom of information must be given priority to winning the trust and ensuring a good Demand Response Program. In good enough conditions to meet end-users' unique needs, a variety of DR modules should also be ready.

\section{The Indian electric grid barriers}

Monitoring systems can play an essential role in reducing residential, commercial, and advanced manufacturing grids. Finally, the transmission and distribution lines' overhead and stress can be reduced. Numerous trade and agriculture demand response systems are being applied in many applications. The configuration of energy management can be managed to perform in congestion management, mainly via models of Real-Time Pricing (RTP) and period-of-Use.

Few demand response programs in the Indian residential sector are used for energy management. The most popular method for reducing high demand is direct load restrictions. However, consumer convenience can be compromised by direct load control. In direct comparison, loads with a lesser impact on the consumer lifestyles are displaced by load-displacement outside peak hours to ensure adequate security for the network. The grid load model "Hung" must be comprehended to examine and consider using the smart grid system's maximum waiting concept. These identifying factors are essential to efficient energy management tools combined with the proper communication and demand management of household charge between consumer and energy utility services.

\section{Conclusions and future work}

Globally, organizations try to convert old grids into smart and dynamic data power systems to address intelligence challenges. Sustainable energy implementation, information management, reliability, network security, etc., are key challenges in SG technology. Although no final solution has been found, several investigations are being tested/ implemented through several pilot projects. There are social-economic problems, but joint efforts are needed to resolve these. The high economic activity associated with these pilot installations is shared with strong support for all investors, governments, and international organizations. Science programmers that offer better understanding and cooperation are organized across various platforms. Like data protection, many other problems, rules, policies, and power theft will be solved.

Data concerning these issues are available. They constitute a valuable base for future work. Future work should also focus on constructing a social network concerning energy issues in smart environments. The platform's role is to inform users about energy consumption throughout the environment and energy loss sources, and recommendations for energy savings. It should also reinforce the involvement of users in the development of sustainable environments.

\section{Declaration of Competing Interest}

The authors declare that they have no known competing financial interests or personal relationships that could have appeared to influence the work reported in this paper.

\section{References}

[1] Balijepalli, V.S.K.M., Pradhan, V., Khaparde, S.A. and Shereef, R.M. Review of Demand Response under Smart Grid Paradigm. Proceedings of the 2011 IEEE PES International Conference on Innovative Smart Grid Technologies-India, Kollam,1-3 December 2011, pp. 236-243. https://doi.org/10.1109/iset-india.2011.6145388

[2] Bulkeley H, McGuirk PM, Dowling R. Making a smart city for the smart grid? The urban material politics of actualising smart electricity networks. Environ Plan A 2016;48(9):1709-26.

[3] Chan, Karin (3 April 2017). "What Is A 'Smart City'?”. Expatriate Lifestyle. Retrieved 23 January 2018.

[4] Chen T. Smart grids, smart cities need better networks. IEEE Netw 2010;24:2-3.

[5] Choi, C.-S., Ian, J.I., Park, W.-K., Jeong, Y.-K., and Lee, I.-W. (2011) Proactive Energy Management System Architecture Interworking with Smart Grid. Proceedings of the IEEE 15th International Symposium on Consumer Electronics, Singapore, 14-17 June 2011, pp.1-4.

[6] Connected Vehicles in Smart Cities: The Future of Transportation Published by interestingengineering.com on 16 November 2018, retrieved on 4 April 2019.

[7] Curiale, M. From smart grids to smart city. In Proceedings of the 2014 Saudi Arabia Smart Grid Conference, SASG, Jeddah, Saudi Arabia, 14-17 December 2014.

[8] De Jong M, Joss S, Schraven D, Zhan C, Weijnen M. Sustainable-smart-resilient-low carbon-eco-knowledge cities; making sense of a multitude of concepts promoting sustainable urbanization. J Clean Prod 2015;109: 25-38.

[9] Dietrich, D.; Bruckner, D.; Zucker, G.; Palensky, P. Communication, and Computation in Buildings: A Short Introduction and Overview. IEEE Trans. Ind. Electron. 2010, 57, pp., 3577-3584.

[10] Ejaz W, Naeem M, Shahid A, Anpalagan A, Jo M. E_cient energy Management for the Internet of Things in Smart Cities. IEEE Commun Mag 2017;55:84-91.

[11] Espe E, Potdar V, Chang E. Prosumer communities and relationships in smart grids: a literature review. Evol Future Direct Energies 2018;11:1-24.

[12] Fallah SN, Deo RC, Shojafar M, Conti M, Shamshirb and S. Computational intelligence approaches for energy load forecasting in smart energy management grids: state of the art. Future Challenges Res Direct Energies 2018;11(596):1-31.

[13] Gungor VC, Sahin D, Kocak T, Ergut S, Buccella C, Cecati C, et al. Smart grid, and smart homes: key players and pilot projects. IEEE Ind Electron Mag 2012;6:18-34.

[14] Harrison C, Eckman B, Hamilton R, Hartswick P, Kalagnanam J, Paraszczak J, et al. Foundations for Smarter cities. IBM J Res Dev 2010;54:1-16.

[15] Hernandez-Callejo L. A comprehensive review of operation and control, maintenance and lifespan management, grid planning and design, and metering in smart grids. Energies 2019;12(1630):1-50.

[16] Hollands Robert G. Will the real smart city, please stand up? City 2008;12(3): 303-20.

[17] Hunt, Dexter; Rogers, Christopher; Cavada, Marianna (2014). "Smart Cities: Contradicting Definitions and Unclear Measures." MDPI Sciforum-The platform for open scholarly exchange. sciforum.net. pp. f004. DOI:10.3390/wsf-4-f004. Retrieved 16 March 2016, pp.1-12.

[18] Ireshika, M.A.S.T. (2014) Home Energy Management System. Universitetet I Agder, Kristiansand \& Grimstad.

[19] Jiang, T., Yu, L. and Cao, Y. (2015) Energy Management of Internet Data Centers in Smart Grid.

[20] Komninos, Nicos (22 August 2013). “What makes cities intelligent?”. In Deakin, Mark (ed.). Smart Cities: Governing, Modelling, and Analysing the Transition. Taylor and Francis. p. 77. ISBN 978-1135124144.

[21] Lai Chun Sing, Jia Youwei, Dong Zhekang, Wang Dongxiao, Tao Yingshan, Lai Qi Hong, et al. A review of technical standards for smart cities. Clean Technologies 2020;2(3):290-310. https://doi.org/10.3390/cleantechnol2030019.

[22] Liserre M, Sauter T, Hung JY. Future energy systems: integrating renewable energy sources into the smart power grid through industrial electronics. IEEE Ind Electron Mag 2010;4:18-37. 
[23] Masera Marcelo, Bompard Ettore F, Profumo Francesco, Hadjsaid Nouredine. Smart (electricity) grids for smart cities: assessing roles and societal impacts. Proc IEEE 2018;106(4):613-25.

[24] McCluer, M. Cleantech 2009: Innovations, Opportunities, and Building Business; Dept. Energy, Office of Energy Efficiency and Renewable Energy: Washington, DC, USA, 2010.

[25] McLaren, Duncan; Agyeman, Julian (2015). Sharing Cities: A Case for Truly Smart and Sustainable Cities. MIT Press. ISBN 9780262029728.

[26] Medina Jose, Muller Nelson, Roytelman Ilya. Demand response and distribution grid operations: opportunities and challenges. IEEE Trans Smart Grid 2010;1(2): 193-8. https://doi.org/10.1109/TSG.2010.2050156.

[27] Mohanty SP, Choppali U, Kougianos E. Everything you wanted to know about smart cities: the Internet of things is the backbone. IEEE Consum Electron Mag 2016;5:60-70.

[28] Nam, T.; Pardo, T.A. Smart city as urban innovation: Focusing on management, policy, and context. In Proceedings of the 5th International Conference on Theory and Practice of Electronic Governance, ACM, Tallinn, Estonia, 26-29 September 2011; pp. 185-194.

[29] Palensky P, Dietrich D. Demand side management: demand response, intelligent energy systems, and smart loads. IEEE Trans Ind Inform 2011;7:381-8.

[30] Paracha ZJ, Doulai P. Load management: techniques and methods in electric power system. Proc Int Conf Energy Manage Power Deliv Singapore 1998;3-5:213-7.

[31] Parham, K.; Farmanbar, M.; Rong, C.; Arild, O. Assessing the importance of energy management in smart homes. In Proceedings of the 4th International Conference on Viable Energy Trends (InVEnT-2019), Istanbul, Turkey, 26-28 April 2019.

[32] Peris-Ortiz, Marta; Bennett, Dag R.; Yábar, Diana Pérez-Bustamante (2016). Sustainable Smart Cities: Creating Spaces for Technological, Social, and Business Development. Springer. ISBN 9783319408958.

[33] Pratt, R.G.; Balducci, P.J.; Gerkensmeyer, C.; Katipamula, S.; Kintner-Meyer, M.C.; Sanquist, T.F.; Secrest, T.J. The smart grid: An estimation of the energy and CO2 benefits. In Smart Grid Estim. Energy CO2 Benefits; PNNL-19112, Revision 1; Pacific Northwest National Lab. (PNNL): Richland, WA, USA, 2010.
[34] Smart Grid: Enabler of the New Energy Economy; A report by Electricity Advisory Committee. 2008. Available online: https://www.energy.gov/oe/downloads/ smart-grid-enabler-new-energy-economy.

[35] Stephens J, Wilson EJ, Peterson TR. Smart Grid (R) Evolution. Cambridge: Cambridge University Press; 2015.

[36] Suryadevara NK, Biswal GR. Smart Plugs: Paradigms and Applications in the Smart City-and-Smart Grid. Energies 1957;2019:12.

[37] Uslar Mathias, Rohjans Sebastian, Neureiter Christian, Pröstl Andrén Filip, Velasquez Jorge, Steinbrink Cornelius, et al. Applying the smart grid architecture model for designing and validating system-of-systems in the power and energy domain: a European perspective. Energies 2019;12(2):258. https://doi.org/ 10.3390/en12020258.

[38] Washburn D, Sindhu U, Balaouras S, Dines RA, Hayes N, Nelson LE. Helping CIOs understand smart city initiatives. Growth 2009;17:1-17.

[39] Wiser, R.; Bolinger, M. 2009 Wind Technologies Market Report. 2009. Available online: https://ilsr.org/2009-wind-technologies-market-report/.

[40] Yu X, Cecati C, Dillon T, Simões MG. The new frontier of smart grids. IEEE Ind Electron Mag 2011;5:49-63.

[41] Zanella A, Bui N, Castellani A, Vangelista L, Zorzi M. Internet of Things for smart cities. IEEE Internet Things J 2014;1:22-32.

[42] Zhibao Yuan; Haiping Xu, "Pulse power supply with faster response and low ripple current using inductive storage and interleaving technology", CPSS Transactions on Power Electronics and Applications, 5(1), pp. $54-62$.

[43] Shangbin Wu; Yue Wang; Lu Bai, "Deep Convolutional Neural Network Assisted Reinforcement Learning-Based Mobile Network Power Saving", IEEE Access, 8, pp. 93671 - 93681

[44] Yan Ming, Chan Chien Aun, Gygax André F, Yan Jinyao, Campbell Leith, Nirmalathas Ampalavanapillai, et al. Ampalavanapillai Nirmalathas and Christopher Leckie, "Modeling the Total Energy Consumption of Mobile Network Services and Applications”. Energies 2019;12(1):184. https://doi.org/10.3390/ en12010184. 